\title{
Laboratory Investigation of the Hydrophobicity Transfer Mechanism on Composite Insulators Aged in Coastal Service
}

\author{
N. Mavrikakıs \\ Electrical \\ Engineering Dpt, \\ TEI of Crete, \\ Greece \\ mavrikakisnikos@ \\ gmail.com
}

\author{
K. Siderakis \\ Electrical \\ Engineering Dpt, \\ TEI of Crete, \\ Greece \\ ksiderakis@ \\ staff.teicrete.gr
}

\author{
E. Koudoumas \\ Electrical \\ Engineering Dpt, \\ TEI of Crete, \\ Greece \\ koudoumas@ \\ staff.teicrete.gr
}

\author{
E.Drakakis \\ Electrical \\ Engineering Dpt, \\ TEI of Crete, \\ Greece \\ edrakakis@ \\ staff.teicrete.gr
}

\author{
E. Kymakis \\ Electrical \\ Engineering Dpt, \\ TEI of Crete, \\ Greece \\ kymakis@ \\ staff.teicrete.gr
}

\begin{abstract}
Silicone rubber (SIR) insulators are known to maintain their surface hydrophobicity even under severe pollution conditions in contrast to the other composite insulator materials used at the last decades. This critical advantage of silicone rubber insulators has made them dominant in high voltage power systems despite the fact that there are other composite materials with better static hydrophobicity. In service conditions, priority is given to the dynamic performance of hydrophobicity due to the unpredictable environmental pollution conditions. This dynamic performance of silicone rubber insulators is also known as hydrophobicity transfer mechanism. In literature, the hydrophobicity transfer mechanism of silicone rubber is related to the reorientation of methyl-groups and the existence of low molecular weight components. However there are many parameters which can change the effectiveness of this mechanism. Some of them referred to the ageing effects on the material structure. Thus it is of great importance to investigate the hydrophobicity transfer mechanism of field aged composite insulators. For this reason a new experimental procedure is introduced based on Cigre TB 442. The results of field aged insulators are compared to that of a new SIR insulator revealing the superiority of silicone rubber even after 17 years of field ageing.
\end{abstract}

Keywords-hydrophobicity; recovery; transfer; field; ageing; silicone rubber; $\mathrm{LMW}$ components, $\mathrm{SiO}_{2}$

\section{INTRODUCTION}

Environmental pollution is one of the most significant factors which can affect the reliability of high voltage power systems [1- 4]. In literature, many network failures have been recorded relating to the environmental pollution of insulators, especially for traditional ceramic insulators [2-6]. The problem of environmental pollution was commonly dealt with by washing traditional ceramic insulators, usually using water in high pressure with the aid of helicopters [2, 4]. This method has a lot of disadvantages that includes cost, risks, need for frequent cleaning, defining the optimum schedule and the breakdown of electricity along the transmission line under cleaning. During the last twenty years, a large percentage of power network operators decided to switch to hydrophobic insulators and coatings [7]. Thus, the faults relating to environmental pollution have been worldwide reduced $[8,9]$. However, the lifetime of composite coatings and insulators is questionable due to their structure vulnerability to ageing factors [10].

During the insulators exposure in service, there are time periods when their hydrophobicity is lost. Then, their behavior is similar to ceramic ones. However, some hydrophobic materials, mainly silicone rubber, are able to recover their original hydrophobicity after a finite time. This advantage of silicone rubber over other composite materials is known as the hydrophobicity transfer mechanism [11]. This feature of silicone rubbers is closely related to the material elemental structure, namely to the reorientation of the side methyl-groups of the polymer molecules and the existence of low molecular weight components. Due to the fact that the hydrophobicity transfer is strongly related to the ageing condition of the material, it is of major importance to investigate the mechanism for field aged insulators, considering that in service conditions the environmental pollution is not predictable and can not be postponed. Thus, the time of hydrophobicity recovery is a critical parameter related to the environmental pollution accumulation rate.

\section{HYDROPHOBICITY TRANSFER}

The ability of surface hydrophobicity recovery following a possible deterioration caused by field stress factors is one of the most significant advantages of silicone rubber. This property is strongly related to the polymer elemental structure. Specifically, two mechanisms are suggested in the literature as dominant for the hydrophobicity transfer:

- reorientation of methyl-groups

- diffusion of low molecular components 


\section{A. Reorientation of methyl-groups}

As it is well known, the low surface energy of silicone rubber is a result of the existence of side methyl groups, which tend to spread out at the interface (Figure 1).

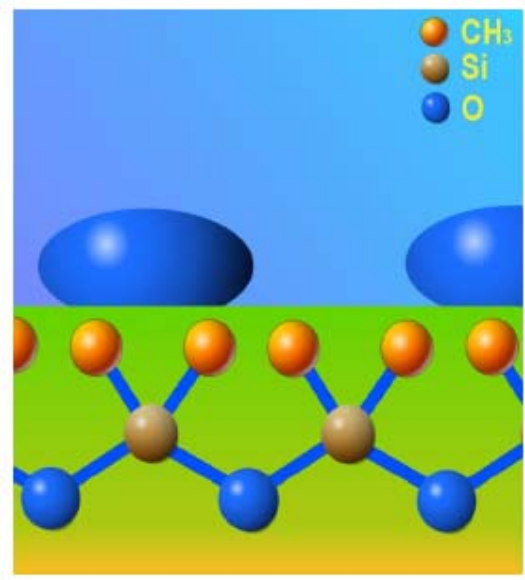

Fig. 1. Structure of silicone rubber.

However the material ageing limits the beneficial hydrophobicity effect of methyl-groups either by imposing the last reorientation towards the inside of the structure or by the scission and replacement of the last with hydroxyl groups. Therefore these reactions contribute to the increase of surface energy and finally to the hydrophobicity loss. In many cases, the recovery of hydrophobicity can be observed after the end of the stress. This is possible, due to the exceptional flexibility of the polymer chains of silicone rubber.

Thus the hydroxyl groups redirect inwardly to the material, restoring finally the methyl groups to the surface. This behavior has been confirmed in the laboratory by implementing salt-fog tests [12-16]. It must be noted that the referred mechanism requires a clean surface, which is not possible in real conditions. In the most of cases the insulator surface is covered with a hydrophilic layer of pollution, which determines the behavior. Furthermore, the insulator surface in service conditions is stressed by electrical activity, thus the requirement of withdrawal of stress is not possible. Therefore, the reorientation of side methyl groups should be considered a secondary recovery mechanism.

\section{B. Diffusion of low molecular weight components}

The main recovery mechanism of hydrophobicity is the diffusion of low molecular weight components of the material. These molecules are already formed in the volume (bulk) of the material during the polymerization procedure $[17,18]$. Considering that the LMW consist of 4 to 14 monomers [19] in comparison to thousands monomers comprised in an average polymer chain, the LMW are quite mobile. These short length backbone chains resulting from curing procedure of polymer move in the volume of the material and tend to migrate from the bulk to the surface when the total surface energy of the material tends to increase. Thereby LMW components penetrate into the surface pollution layer, varying the initial hydrophilic behavior to hydrophobic [20].

This feature is illustrated in Figure 2. Figure 2(a) shows an RTV SIR coated porcelain insulator, which is covered by a layer of environmental pollution. However the insulator presents hydrophobic behavior which is related to the existence of LMW components as illustrated in Figure 2(b). In an attempt to remove the environmental pollution from the insulator surface, a transient loss of hydrophobicity is observed as evident in Figures 2(c) and 2(d).
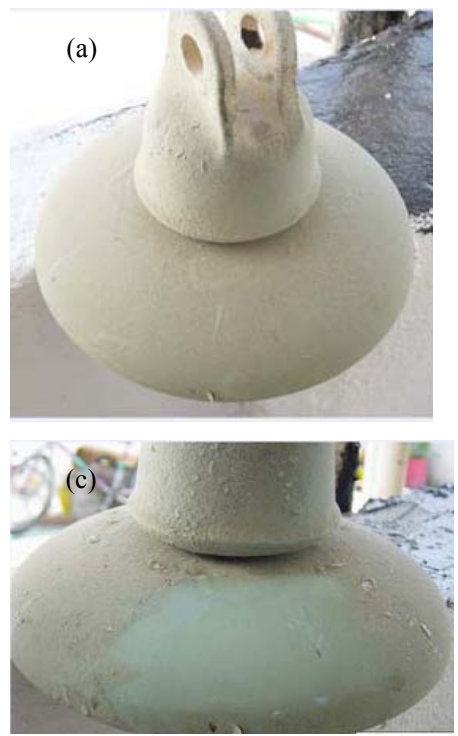

Fig. 2. SIR coated ceramic insulator

The deposition of hydrophilic environmental pollution on the insulator surface may suspend the advantage of a hydrophobic surface. Thus, the presence of low molecular weight components and their ability to diffuse from the volume to surface are of major importance for material efficiency.

\section{HYDROPHOBICITY TRANSFER PARAMETERS}

\section{A. Type and quantity of LMW components}

The hydrophobicity transfer mechanism is mainly based on the diffusion of LMW components from the bulk material to the surface. Therefore the speed and the recovery time depend on the concentration difference between the volume and the surface of the material. Initially the quantity of LMW components is related to the polymerization process followed and the thickness of the material.

The initial amount may be changed during the material lifetime mainly due to ageing procedure. Specifically the natural cleaning [21], the increase of surface heat (evaporation) and procedure relating to crosslinking reactions may result in reduced amounts of LMW molecules. On the other hand, scission of long length backbone chains of polymer can form LWM components. Depending on the conditions and the balance developed, the LMW components exhaustion time is determined [22, 23].

It must be noted that the quantity of molecules is of great importance, namely the type of chain (linear of circular). In 
[24], it was shown that that the presence of cyclic chains is related to the faster recovery time. The latter was confirmed in [25].

\section{B. Relative position of LMW components in the bulk material}

The relative position of LMW components in the bulk material is of great importance for hydrophobicity transfer time. As it is well known, the LMW components move with a finite speed towards the surface. Thus, the closer to the surface the LMW components are, the faster the material recovers. It must be noted that in aged material the amount of LMW components close to the surface is exhausted, thus they emerge from large depth, which requires more time [19, 26].

\section{Material composition}

Due to the low intermolecular forces developed in PDMS molecules, the LMW components present high mobility. However, the existence of fillers, particularly inorganic, can limit the mobility of LMW components due to the friction phenomenon $[23,27]$. It must be noted that ATH which is commonly used as filler in SIR insulators, can contribute to a slower mobility of LMW molecules to the surface [28]. Moreover, higher amount of filler means lower amount of polymer and thus lower quantity of LMW components [22, 27]. Furthermore, the crosslinking reactions during the vulcanization process of the material can create a solid matrix close to the surface of the material preventing the migration of LMW component from the bulk to the surface. The additional crosslinking reactions and the byproducts such as $\mathrm{SiO}_{2}$ come from the surface electrical activity in service conditions can suppress any possibility of hydrophobicity recovery.

\section{Temperature}

As referred, the hydrophobicity transfer mechanism is based on the diffusion of LMW molecules. Thus, in addition to the quantity, the high ambient temperature can accelerate too the mobility of these molecules, achieving faster hydrophobicity recovery $[22,29,30]$.

\section{E. Type of pollutants}

The pollutants' type may affect the possibility of the hydrophobicity recovery through the diffusion of LMW components. As previously referred, the LMW components penetrate into the surface pollution layer, changing its behavior from hydrophilic to hydrophobic. In fact, the LMW components are absorbed by the surface layer of soil, characterized by the higher surface energy than that of the material [31]. Specifically, the higher the energy difference between the pollution layer and the material, the stronger the LMW molecules absorption from the pollutants. Thus the pollutants' structure [31-34] and their concentration can essentially determine the hydrophobicity transfer speed. Table I is referred to the mobility of LMW components depending on the pollutants' type. It must be noted that in the case of the material hydrophobicity transfer loss, its original hydrophobicity can be recovered by cleaning the material surface. Various methods were tried in [35] in field conditions. The most acceptable method is the insulator cleaning with high pressure water as well as in the case of the uncoated insulators [36].

TABLE I. POLLUTION EFFECT ON THE MOBILITY OF LMW

\begin{tabular}{|c|c|l|}
\hline \multicolumn{2}{|c|}{ Type of pollutants } & \multicolumn{1}{c|}{ Mobility of LMW components } \\
\hline Inert & $\begin{array}{c}\text { Kieselguhr, } \\
\text { Caolin, Clay }\end{array}$ & $\begin{array}{l}\text { In the case of Kieselguhr and clay the } \\
\text { diffusion is very easy. The same is for } \\
\text { caolin clay (longer hydrophobicity } \\
\text { transfer time [33, 34] ). }\end{array}$ \\
\hline $\begin{array}{c}\text { Metal } \\
\text { oxides }\end{array}$ & $\begin{array}{c}\mathrm{SiO}_{2}, \mathrm{ZnO}, \\
\mathrm{Fe}_{2} \mathrm{O}_{3}, \mathrm{Al}_{2} \mathrm{O}_{3} .\end{array}$ & $\begin{array}{l}\text { Hydrophobicity transfer is achieved } \\
\text { between a time interval of } 12 \mathrm{~h} \text { and } 24 \mathrm{~h} \\
{[32,33]}\end{array}$ \\
\hline $\begin{array}{c}\text { Inorgani } \\
\text { c salts }\end{array}$ & $\begin{array}{c}\mathrm{BaSO}_{4}, \mathrm{CaSO}_{4}, \\
\mathrm{ZnSO}_{4}, \mathrm{NH}_{4} \mathrm{Cl},\end{array}$ & $\begin{array}{l}\text { Limited mobility, longer hydrophobicity } \\
\text { transfer time is required [33, 34]. }\end{array}$ \\
\hline Mixtures & $\begin{array}{c}\mathrm{Clay}+\mathrm{NaCl}_{2}, \\
\mathrm{Clay}+\mathrm{CaSO} \mathrm{Na}_{4}\end{array}$ & $\begin{array}{l}\text { The behavior depends on the content, } \\
\text { according to the above behavior [33, 34]. }\end{array}$ \\
\hline
\end{tabular}

\section{EXPERIMENTAL PROCEDURE}

In order to investigate the effect of field ageing factors on the hydrophobicity transfer mechanism of composite insulators in service the following procedure was adopted. Two fieldaged $150 \mathrm{kV}$ SIR insulators operating in the transmission system of Crete were removed from the lines. The insulators were operating for a period of 17 years in different locations, characterized by different pollution severity, of the coastal high voltage network of Crete (Figure 3) [37-40]. Table II summarizes the main details for the field aged insulators examined and the pollution severity of their locations.

The insulators were from different manufacturers, thus they were differing in material composition. The results of fieldaged insulators are compared to these of a new one SIR insulator, used as reference. The fact that the insulators did not present failures during their 17 years of operation indicates the effective condition of the hydrophobicity. The experimental procedure, implemented in this study, has been introduced in Cigre TB 442 of WG D1.14. An artificial pollution slurry made of $70 \%$ silica powder $\mathrm{SiO}_{2}$ and $30 \%$ of water by weight was applied on the sample's surface as illustrated in Figure 5. The total thickness of the pollution layer on the sample's surface was less than $0.5 \mathrm{~mm}$.

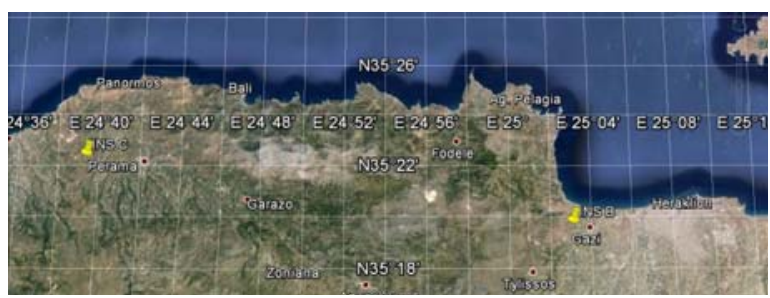

Fig. 3. Location of field-aged composite insulators

TABLE II. INSULATORS’ DETAILS

\begin{tabular}{|c|c|c|c|}
\hline Insulator & $\begin{array}{c}\text { Polymeric } \\
\text { material }\end{array}$ & $\begin{array}{c}\text { Years in } \\
\text { service }\end{array}$ & $\begin{array}{c}\text { Pollution } \\
\text { severity }\end{array}$ \\
\hline A & SIR & New & - \\
\hline B & EPDM \& ATH & 17 & Heavy \\
\hline C & SIR\& ATH & 17 & Medium \\
\hline
\end{tabular}




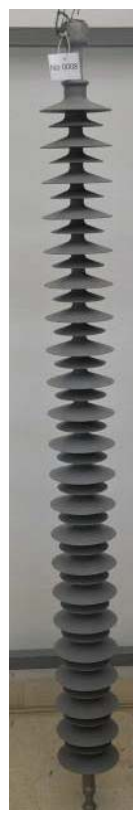

A

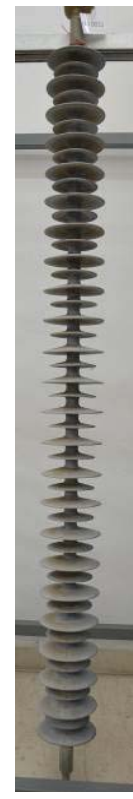

B

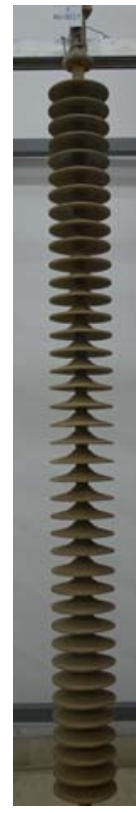

$\mathrm{C}$
Fig. 4. The three composite insulators

Prior to the deposition of the artificial pollution slurry on the sample's surface, the upper shed of the polymeric housing of the field aged insulator was removed. Samples about $10 \mathrm{~mm}$ x $10 \mathrm{~mm}$ x $5 \mathrm{~mm}$ were created from these sheds. The samples were cleaned with deionized water and stored in dry conditions for 24 hours. After that the initial contact angle was measured for each sample, which was used as reference point for each sample.

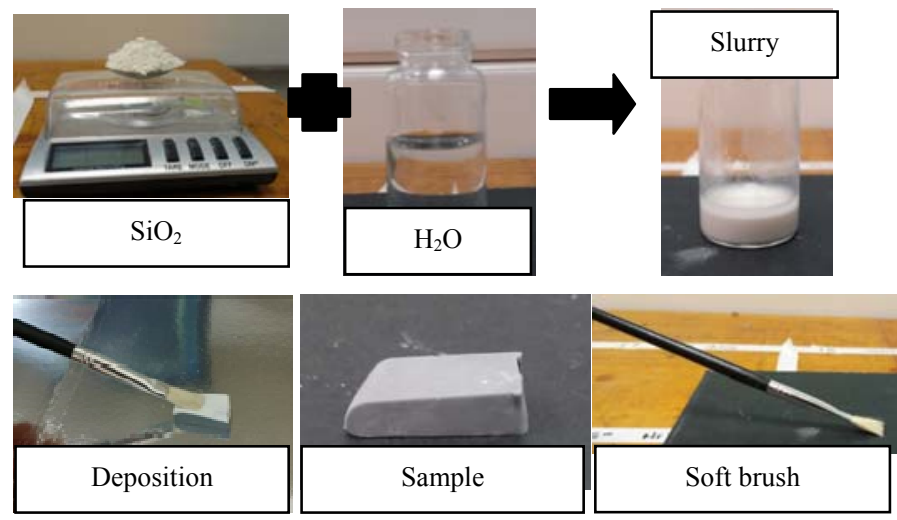

Fig. 5. Deposition of artificial pollution slurry on sample's surface

After that, the artificial pollution slurry was applied on the samples' surfaces as illustrated in Figure 5. Following the contact angle, indicator of hydrophobicity condition, of each sample was measured in certain time intervals. During the contact angle measurements, the conditions were constant, namely the ambient temperature was $23^{\circ} \mathrm{C}$, the relative humidity was $50 \%$ and the barometric pressure was $755 \mathrm{~mm}$ $\mathrm{Hg}$.

\section{RESULTS}

Water droplets, $10 \mu \mathrm{l}$ in volume, were applied on the artificial polluted samples' surfaces. The angle formed between the water droplet and the surface of the sample was measured with the KSV-CAM 101 instrument according to method A of IEC 62073. The measurements were taken in certain time intervals within 24 hours. The evaluation of hydrophobicity transfer mechanism is achieved by analyzing the recorded contact angle measurements. The contact angle measurements after the deposition of the artificial pollution slurry were compared to the initial contact angle in order to evaluate the hydrophobicity transfer speed.
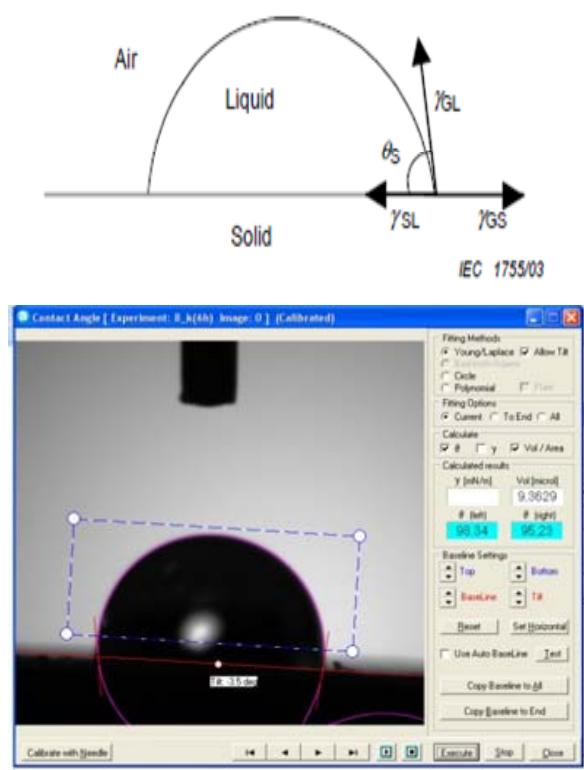

Fig. 6. Measure of contact angle

Changes of hydrophobicity for the field-aged and the new one composite insulators during the experimental procedure are presented in Figure 7.

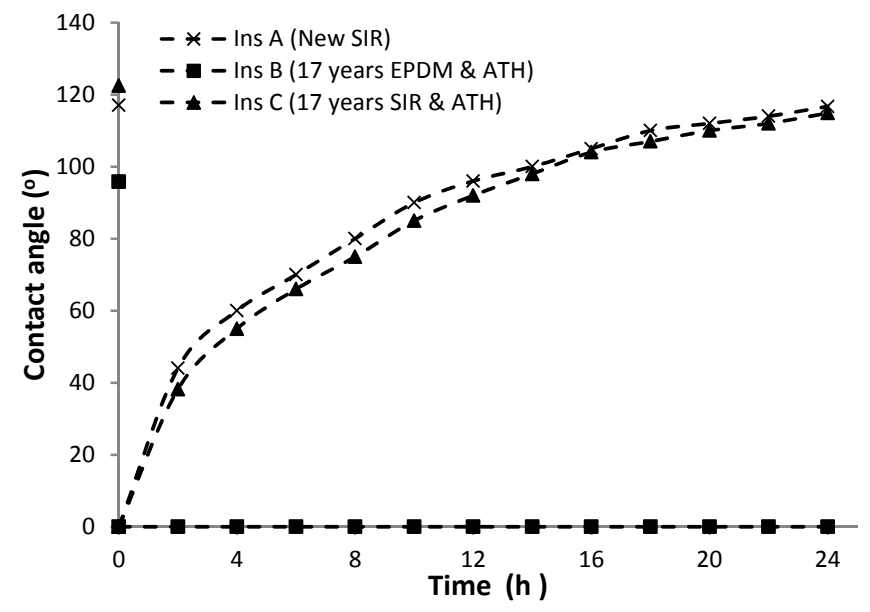

Fig. 7. Hydrophobicity transfer speed of insulators 
As previously referred, hydrophobicity transfer is a feature of silicone rubbers. Both the field aged and the new SIR (Figure 7) insulators were found to be able to recover their origin surface hydrophobicity within 24 hours in contrast to field-aged EPDM insulator. The surface hydrophobicity of the latter is strongly related to the hydrophobicity behavior of the artificial pollution slurry deposited on its surface. In this study the initial hydrophobic EPDM insulator was changed to hydrophilic after its pollution deposition. That means that in service conditions EPDM insulators are hydrophobic only immediately after their cleaning, thus they may effectively operate for long time in areas with light pollution severity.

The hydrophobicity transfer mechanism was detected for both SIR insulators. The results showed that the hydrophobicity transfer speed of the field aged insulator is comparable to that of the new SIR insulator without presenting significant differences. The results are in good agreement with that presented in Table I. According to that, the hydrophobicity transfer time of SIR insulators in the case of $\mathrm{SiO}_{2}$ pollutants is estimated from 12 to 24 hours. In this study the surface hydrophobicity of SIR insulators changed from hydrophilic (contract angle $<90^{\circ}$ ) to hydrophobic (contact angle $>90^{\circ}$ ) after $12 \mathrm{~h}$ from the artificial pollution slurry deposition and they finally recovered they initial hydrophobicity within 24 hours.

\section{CONCLUSIONS}

Surface hydrophobicity is of the most significant advantages of composite insulators compared to traditional ceramic insulators. Some materials such as SIR have the feature to gradually recover their lost hydrophobicity in the case of their deposition with hydrophilic environmental pollution. This property is known as the hydrophobicity transfer mechanism and it is closely related to the condition of the material and the conditions exposed. In this study, a short review to the hydrophobicity transfer mechanism was performed and following results for two field aged and a new composite insulator, used as reference, were presented by introducing an experimental procedure based on Cigre TB 442 . As expected, a hydrophobicity transfer mechanism was not found for the EPDM insulator. On the other hand, both SIR insulators were able to recover their surface hydrophobicity within 24 hours. The non-significant differences between the field-aged and the new insulator are mainly related to the different material composition of insulators and the field ageing effects. Considering that the SIR insulator was removed from service after 17 years, its hydrophobicity performance can be considered excellent.

\section{ACKNOWLEDGMENT}

This work was partly supported by the Polydiagno research project (project code 11SYN-7-1503) which is implemented through the Operational Program "Competitiveness and Enterpreneurship". Action "Cooperation 2011" and is cofinanced by the European Union and Greek national funds (National Strategic Reference Framework 20072013).

\section{REFERENCES}

[1] J. S. T. Looms, Insulators for high voltages, IEE Power Engineering Series, ed.7, 1987

[2] CIGRE WG 33-04-01, Polluted insulators: a review of current knowledge, No.158, 2000

[3] NGK, Technical Guide, NGK Insulators LTD, No.91-R, 1991

[4] R. S. Gorur, Outdoor Insulators, R. S. Gorur, 1999

[5] CIGRE WG 33-04, "The measurement of site pollution severity and its application to insulator dimensioning for A.C. systems", ELECTRA, Vol. 64, pp. 101-116, 1979

[6] CIGRE WG 36-01, Electric Power Transmission and the Environment: Fields, Noise and Interference, Cigre, 1993

[7] J. F. Hall, "History and bibliography of polymeric insulators for outdoor applications", IEEE Transactions on Power Delivery, Vol. 8, No.1, pp. 376-385, 1993

[8] CIGRE WG 22-03, "World wide experience with high voltage composite insulators", ELECTRA, No. 191, 2000

[9] S. M. Gubanski, R. Hartings, "Swedish research on the application of composite insulators in outdoor insulation", Electrical Insulation Magazine, Vol. 11, No.5, pp. 24-31, 1995

[10] R. Hackam, "Outdoor HV composite polymeric insulators", IEEE Transactions on Dielectrics and Electrical Insulation. Vol.6, No.5, pp. $557-585,1999$

[11] CIGRE WG D1.14, Evaluation of dynamic hydrophobicity properties of polymeric materials for non - ceramic outdoor insulation - Retention and transfer of hydrophobicity, Material properties for non-ceramic outdoor insulation, TB 442, 2010

[12] J. Kim, M. K. Chaudhury, M. J. Owen, "Hydrophobicity loss and recovery of Silicone HV insulation", IEEE Transactions on Dielectrics and Electrical Insulation, Vol. 6, No.5, pp. 695-702, 1999

[13] H. Hillborg, W. Gedde, "Hydrophobicity changes in Silicone Rubbers", IEEE Transactions on Dielectrics and Electrical Insulation, Vol. 6, No. 5, pp. 703-717, 1999

[14] S. H. Kim, E. A. Cherney, R. Hackam, "Hydrophobic behavior of insulators coated with RTV Silicone Rubber", IEEE Transactions on Electrical Insulation,Vol. 27, No. 3, 1992

[15] J. W. Chang, R. S. Gorur, "The role of the backbone chain rotation in the hydrophobicity recovery of polymeric materials for outdoor insulation", Proceedings of the $4^{\text {th }}$ international conference on Conduction and breakdown in solid dielectrics, pp.270-274, 1992

[16] R. S. Gorur, J. W. Chang, O .G, Amburgey, "Surface hydrophobicity of polymers used for outdoor insulation", IEEE Transactions on Power Delivery, Vol. 5, No. 4, pp. 1923-1933, 1990

[17] M. J. Owen, "Siloxane polymers", PTR Prentice Hall, 1993

[18] W. Noll, "Chemistry and Technology of Silicones", New York: Academic Press, 1968

[19] R. S. Gorur, G. G. Karady, A. Jagota, M. Shah, A. M. Yates, "Aging in silicone rubber used for outdoor insulation", IEEE Transactions on Power Delivery, Vol. 7, No.2, pp. 525-538, 1992

[20] K. Chrzan, Z. Pohl, "Hygroscopic properties of pollutants on HV insulators", IEEE Transactions on Electrical Insulation, Vol. 24, No.1, pp. 107-112, 1989

[21] H. Deng, R. Hackam. "Impact of weather conditions and formulations on LMW Silicone Fluid content in RTV Silicone Rubber Coatings", Conference on Electrical Insulation and Dielectric Phenomena, San Fransisco, USA, pp. 437-440, 1996

[22] J. W. Chang, R. S. Gorur, "Surface recovery of Silicone Rubber used for HV outdoor insulation", IEEE Transactions on Dielectrics and Electrical Insulation, Vol. 1, No.6, pp. 1039-1046, 1994

[23] H. Deng, R. Hackam, "Low molecular weight silicone fluid in RTV Silicone Rubber Coatings", IEEE Transactions on Dielectrics and Electrical Insulation, Vol.6, No.1, pp. 84-94, 2000

[24] H. Janssen, A. H., H. C. Karner, "LMW components in silicone rubbers and epoxy resins", Conference on International Symposium on High Voltage Engineering, London, UK, IEE, 1999 
[25] S. Kumagai, N. Yoshimura, "Hydrophobic Transfer of RTV Silicone Rubber aged in single and multiple environmental stresses and the behaviour of LMW silicone fluid", IEEE Transactions on Power Delivery, Vol. 18, No. 2, pp. 506-516, 2003

[26] H. Homma, T. Kuroyagi, K. Izumi, C. L. Mirley, J. Ronzello, S. A. Boggs, "Diffusion of Low molecular weight siloxane from bulk to surface", IEEE Transactions on Dielectrics and Electrical Insulation, Vol. 6, No.3, pp. 370-375, 1999

[27] H. Deng, R. Hackam, E. A. Cherney, "Influence of thickness, substrate type, amount of silicone fluid and solvent type on the electrical performance of RTV SIR Coatings", IEEE Transactions on Power Delivery, Vol. 11, No. 1, pp. 431-443, 1996

[28] S. H. Kim, E. A. Cherney, R. Hackam, "Effects of filer level in RTV Silicone rubber Coatings used in HV Insulators", IEEE Transactions on Electrical Insulation, Vol. 27, No.6, pp. 1065-1072, 1991

[29] H. Jahn, R. Barsch, E. Wendt. "The influence of temperature on the recovery of the hydrophobicity on silicone rubber surfaces", Conference on Electrical Insulation and Dielectric Phenomena, IEEE, pp. 242-245, 2000

[30] K. O. Papailiou, F. Schmuck, Y. Voyatzakis, "Silicone Rubber performance in respect to Mediterranean Environment", Conference on Contamination Issues on High Voltage Insulators, Heraklion, Greece, 2001

[31] W. Shaowu, L. Xidong, C. Zixia, W. Xun, L. Zhi, Z. Yuanxiang, Y. Yu, W. Liming, G. Zhicheng, "Hydrophobicity changing of Silicone Rubber insulators in Service", Cigre Session 2002, Paris, 2002

[32] W. Shaowu, L. Xidong, G. Zhicheng, W. Xun. "Hydrophobicity transfer properties of silicone rubber contaminated by different kinds of pollutants", Conference on Electrical Insulation and Dielectric Phenomena, Canada, pp. 373-376, 2000

[33] F. Exl, J. Kindersberger, R. Barsch, F. Gerdinand, "Round robin test for the evaluation of the hydrophobicity transfer ability of polymeric insulating materials", ETG Fachtanggung, Grenzflachen in elektrischen isoliersystemen, Vol. 8, No. 9, 2005

[34] J. Zhidong, G. Haifeng, W. Liming, G. Zhicheng, Y. Jie, "Effects of contaminations on hydrophobicity transference of RTV SIR coating", Conference on International Symposium on High Voltage Engineering, Netherlands, 2003

[35] S. H. Kim, E. A. Cherney, R. Hackam,"Artificial testing and evaluation of RTV coatings in a salt fog chamber", IEEE Transactions on Electrical Insulation, Vol. 26, No.4, pp. 797-805, 1991

[36] IEEE Std 957-1995, IEEE Guide for cleaning insulators, IEEE PES, 1995.

[37] D. Pylarinos, K. Siderakis, E. Thalassinakis, N. Mavrikakis, E. Koudoumas, E. Drakakis, E. Kymakis, "A New Approach for Open Air Insulator Test Stations: Experience From Talos and the Polydiagno Project", Journal of Electrical Engineering, Vol. 16, No. 2, Art. No. 16.2.32, pp. 269-273, 2016

[38] M. Dimitropoulou, D. Pylarinos, K. Siderakis, E. Thalassinakis, M. Danikas, "Comparative Investigation of Pollution Accumulation and Natural Cleaning for Different HV Insulators", Engineering, Technology \& Applied Science Research, Vol. 5, No. 2, pp. 764-774, 2015

[39] M. Dimitropoulou, D. Pylarinos, K. Siderakis, E. Thalassinakis, M. Danikas, "Insulation coordination and pollution measurements in the island of Crete", ICPADM International Conference on the Properties and Applications of Dielectric Materials, Sydney, Australia, July 19-22, 2015

[40] D. Pylarinos, K. Siderakis, E. Thalassinakis,"Comparative Investigation of Silicone Rubber Composite and Room Temperature Vulcanized Coated Glass Insulators Installed in Coastal Overhead Transmission Lines", IEEE Electrical Insulation Magazine, Vol. 31, No. 2, pp. 23-29, 2015 